\title{
Exclusion of BMP6 as a Candidate Gene for Cleidocranial Dysplasia
}

Jeffrey W. Innis, ${ }^{1,2 *}$ James H. Asher, Jr., ${ }^{4}$ Yong Liang, ${ }^{4}$ Aihui Wang, ${ }^{4}$ Charles M. Wilke, ${ }^{1}$ Herman A. Dierick, ${ }^{1}$ Kristin Kazen-Gillespie, ${ }^{1}$ Susan Sheldon, ${ }^{3}$ Thomas W. Glover, ${ }^{1,2}$ and Thomas B. Friedman ${ }^{4}$

${ }^{1}$ Department of Human Genetics, University of Michigan, Ann Arbor

${ }^{2}$ Department of Pediatrics, University of Michigan, Ann Arbor

${ }^{3}$ Department of Pathology, University of Michigan, Ann Arbor

${ }^{4}$ Genetics Graduate Program, Michigan State University, East Lansing

Cleidocranial dysplasia (CCD) is an autosomal dominant, generalized skeletal dysplasia in humans that has been mapped to the short arm of chromosome 6. We report linkage of a CCD mutation to $6 \mathrm{p} 21$ in a large family and exclude the bone morphogenetic protein 6 gene (BMP6) as a candidate for the disease by cytogenetic localization and genetic recombination. CCD was linked with a maximal two-point LOD score of 7.22 with marker D6S452 at $\theta=0$. One relative with a recombination between D6S451 and D6S459 and another individual with a recombination between D6S465 and CCD places the mutation within a $7 \mathrm{cM}$ region between D6S451 and D6S465 at 6p21. A phage P1 genomic clone spanning most of the BMP6 gene hybridized to chromosome 6 in band region p23-p24 using FISH analysis, placing this gene cytogenetically more distal than the region of linkage for CCD. We derived a new polymorphic marker from this same P1 clone and found recombinations between the marker and CCD in this family. The results confirm the map position of CCD on 6p21, further refine the CCD genetic interval by identifying a recombination between D6S451 and D6S459, and exclude BMP6 as a candidate gene. Am. J. Med. Genet. 71:292297, 1997. ๑ 1997 Wiley-Liss, Inc.

Contract grant sponsor: University of Michigan Multipurpose Arthritis and Musculoskeletal Diseases Center; Contract grant number: NIH 5P60AR20557: Contract grant sponsor: Scott Collins Memorial Fund; Contract grant sponsor: National Institute of Deafness and Other Communication Disorders, National Institutes of Health; Contract grant number: RO1DC02407.

*Correspondence to: Dr. Jeffrey W. Innis, University of Michigan, Department of Human Genetics, Med. Sci. II, M4708, Ann Arbor, MI 48109-0618.

Received 31 July 1996; Accepted 29 January 1997
KEY WORDS: genetic mapping; cleidocranial dysplasia; bone morphogenetic protein 6; autosomal dominant; clavicle

\section{INTRODUCTION}

Cleidocranial dysplasia, CCD (MIM 119600), is an autosomal dominant, generalized skeletal dysplasia in humans characterized by short stature, delayed ossification of the large fontanels and sutures of the skull, wormian bones, midface hypoplasia, late eruption of permanent teeth, malformed dental roots, enamel hypoplasia, supernumerary teeth, aplasia or hypoplasia of the clavicles, other skeletal abnormalities, and normal intelligence [Gorlin et al., 1990 and references therein; Spranger et al., 1974; Chitayat et al., 1992; Jensen and Kreiborg, 1990]. The skull, clavicles, and teeth exhibit the most apparent clinical abnormalities. There is often a wide range of variability within a family.

Brueton et al. [1992] described a mother and daughter and an unrelated individual with apparent CCD associated with rearrangements involving 8q22. Neinhaus et al. [1993] described a pericentric inversion involving chromosome 6 in a patient with CCD. Recently, four groups have localized the CCD gene using linkage analysis to the proximal short arm of chromosome 6 in several families [Feldman et al., 1995; Gelb et al., 1995; Mundlos et al., 1995; Ramesar et al., 1996]. Even with the localization of the CCD gene to chromosome $6 \mathrm{p}$ in several families, genetic heterogeneity remains a possibility. The gene for bone morphogenetic protein- 6 (BMP6) is a strong candidate for the CCD gene due to its position on the short arm of chromosome 6 and its expression pattern [Lyons et al., 1989; Hahn et al., 1992].

We identified a large family segregating cleidocranial dysplasia and sought to determine whether CCD in this family is linked to $6 \mathrm{p}$ and, if so, whether the BMP6 gene was located within the CCD genetic interval. 


\section{MATERIALS AND METHODS DNA Preparation}

DNA was prepared from whole blood using a Puregene kit (Gentra Systems, Inc.). Thirty nanograms of genomic DNA were used for amplification under standard reaction conditions and 28 cycles of PCR [Weber et al., 1993].

\section{Polymorphic Markers}

All STR primer pairs, with the exception of D6S2257, (shown in Table I) were obtained from Research Genetics, Inc. For the new STR, D6S2257, derived from a phage P1 genomic clone spanning most of the BMP6 gene, total P1 DNA was digested with Sau3AI, subcloned into BamHI-cut, calf intestine alkaline phosphatase-treated phagemid vector pBluescript II KS+, and individual colonies were screened with an alkaline phosphatase-linked CA repeat probe (25-32 nucleotides long) and visualized using a Quick-Light Genome Mapping Probe kit (FMC Corp.). One positive clone (GenBank accession number U63119) was sequenced and found to have multiple complex dinucleotide repeat. The sequence of this new STR (D6S2257) was PCR amplified with primers TF213: 5'-AACTCCCACATCGTTCAAGG-3' and TF214: 5'-GGGCCAGGAGTAAAGACACA-3'. Allele sizes and frequencies for D6S2257 were determined by PCR using DNA from 51 unrelated individuals. This marker amplified somatic cell hybrid DNA (NIGMS Human/Rodent somatic cell hybrid mapping panel 2, NA 10629) containing only human chromosome 6 (data not shown). The same preparation of P1 DNA allowed for amplification of both D6S2257 and BMP6-specific PCR products. PCR products were labelled during synthesis using $\alpha-{ }^{33} \mathrm{P}-$ dCTP and separated by electrophoresis on $6.5 \%$ denaturing polyacrylamide gels adjacent to sequencing ladders and PCR products from CEPH DNA samples whose allele sizes were known. Alleles were typed according to fragment sizes independently by three investigators prior to linkage analysis. No parentage discrepancies were identified in this family. With one exception, all STRs exhibited Mendelian segregation. For the longest PCR products of D6S2257 allelic instability was observed.

\section{Linkage Analyses}

Two-point linkage analyses were performed with ILINK and MLINK [Ott, 1991].

\section{P1 Genomic Clone}

A human P1 genomic clone library [Sternberg 1990, 1992] was screened with PCR primers derived from the $3^{\prime}$ untranslated sequence of the published BMP6 cDNA [Celeste et al., 1990]. The primers were 5'CAGTGCCTTATTACCCAGGAAG-3' and $5^{\prime}$ TGGGAATGAACTGAACAGAGG-3', which amplify a 370 base pair product from human genomic DNA. One $\mathrm{P} 1$ clone was isolated by a hierarchical, pooled screening strategy. This clone, P1-BMP6, was shown by PCR and Southern blotting with BMP6 cDNA fragments to harbor most of the BMP6 gene (data not shown). P1 clone DNA was purified with a Qiagen Plasmid Maxi Kit.

\section{FISH}

FISH analysis was carried out using standard, previously reported procedures [Wilke et al., 1996]. Metaphase chromosomes from a normal control were prepared after PHA stimulation of whole blood lymphocytes and hybridized with a biotinylated (biotin-14dATP) probe prepared using the BioNick Labeling System (BRL, Gaithersburg, MD) from total P1-BMP6 clone DNA. Two hundred nanograms of biotinylated probe and $10 \mu \mathrm{g}$ of human Cot1 DNA (BRL, Gaithersburg, MD) were denatured at $75^{\circ} \mathrm{C}$ in $10 \mu \mathrm{l}$ of $2 \times \mathrm{SSC}$, $10 \%$ dextran sulfate, $50 \%$ formamide, and $1 \%$ Tween 20 , and preannealed at $37^{\circ} \mathrm{C}$ for at least 1 hour prior to application to denatured slides. Slides were denatured at $70^{\circ} \mathrm{C}$ for 2 minutes in $70 \%$ formamide, $2 \times \mathrm{SSC}, \mathrm{pH}$ 7.0, followed by a standard dehydrating ethanol wash series. The hybridization of each slide was carried out

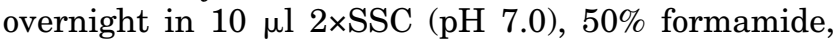
$10 \%$ dextran sulfate, and $1 \%$ Tween 20 at $37^{\circ} \mathrm{C}$. Slides were washed once in $50 \%$ formamide, $2 \times \mathrm{SSC}$ at $42^{\circ} \mathrm{C}$ followed by $0.1 \times \mathrm{SSC}$ at $60^{\circ} \mathrm{C}$. Signals were visualized after incubations with FITC conjugated avidin-DCS and biotinylated goat anti-avidin IgG (Vector Labs, Burlingame, CA), followed by counterstaining with propidium iodide alone or with both DAPI and propidium iodide. The chromosomes were viewed with either a Nikon or Zeiss Axioskop epifluorescence microscope equipped with FITC and DAPI filters. Thirteen separate normal chromosome spreads were photographed. Metaphase spreads prepared from CCDaffected individual III-14 fibroblasts were hybridized with the same probe and revealed two signals in each cell examined (data not shown).

\section{RESULTS}

Twenty-one relatives spanning three generations of a pedigree segregating CCD were examined by two of us (J.W.I. and J.H.A.). All 13 affected relatives showed characteristics of cleidocranial dysplasia (Fig. 1). Lymphocyte chromosome analysis showed no anomalies at the 800 band level in an affected relative (III-12, data not shown). DNA typing for markers on $8 \mathrm{q}$ showed no linkage with CCD in this family (data not shown); however, several markers on chromosome $6 p$ showed tight linkage. The pedigree and haplotypes for linked markers are shown in Figure 1. The data are summarized in Table I. CCD was linked to D6S451 with a LOD score of 5.4 at $\theta=0.038$, D6S459 with a LOD score of 5.1 at $\theta=0$, D6S452 with a LOD score of 7.22 at $\theta=0$, and D6S438 with a LOD score of 4.8 at $q=0$. The CEPH map indicates that the linkage order for these markers is tel-D6S451-2cM-D6S459-4cM-D6S438-1cMD6S465-cen [Gyapay et al., 1994]. Two point LOD score analysis with this family confirmed this marker order (data not shown). One affected person (IV-10) in this CCD family carries a chromosome with a recombination between D6S451 and D6S459 and an unaffected individual (II-3) carries a recombination between D6S465 and CCD. These recombinants allowed 
TABLE I. Pairwise Lod Scores (Z) at Different Recombination Fractions $(\theta)$ Between CCD and Chromosome 6 Markers

\begin{tabular}{lccccccc}
\hline Locus & 0.0 & 0.1 & 0.2 & 0.3 & 0.4 & $\hat{\theta}$ & $\hat{\mathrm{Z}}$ \\
\hline D6S291 & $-\infty$ & -0.05 & 0.144 & 0.186 & 0.133 & 0.286 & 0.187 \\
D6S451 & $-\infty$ & 5.035 & 4.007 & 2.681 & 1.120 & 0.038 & 5.367 \\
D6S459 & 5.117 & 4.202 & 3.179 & 2.028 & 0.777 & 0.000 & 5.117 \\
D6S452 & 7.225 & 5.989 & 4.609 & 3.050 & 1.318 & 0.000 & 7.225 \\
D6S438 & 4.816 & 3.947 & 2.976 & 1.886 & 0.719 & 0.000 & 4.816 \\
D6S269 & 5.283 & 4.289 & 3.226 & 2.097 & 0.895 & 0.000 & 5.283 \\
D6S465 & $-\infty$ & 1.492 & 1.266 & 0.860 & 0.391 & 0.090 & 1.495 \\
\hline
\end{tabular}

us to position the CCD mutation within a $7 \mathrm{cM}$ region between D6S451 and D6S465 (Fig. 2).

A potential candidate gene for CCD, BMP6, is known to map to this general region of human chromosome 6 [Hahn et al., 1992; Volz et al., 1994]. BMP6 is known to be expressed in a wide variety of organs including the calvaria of the developing mouse [Lyons et al., 1989]. RT-PCR of fibroblast mRNA from individual III-14 showed no differences in the BMP6 mRNA sequence corresponding to the mature protein of this TGF $\beta$-like molecule (data not shown). We screened a human phage P1 genomic library with primers derived from the $3^{\prime}$ untranslated sequence of the human BMP6 gene and isolated a clone spanning part of the BMP6 locus. This clone allowed for specific amplification of portions of the BMP6 gene by PCR. A partial restriction map was constructed by Southern blot analysis using nonrepetitive probes from the $3^{\prime}$ half of the BMP $6 \mathrm{cDNA}$ (data not shown). CCD-affected individual DNA samples showed no rearrangements by Southern blotting compared with normal controls (data not shown). We used this P1 clone as a probe in FISH analysis on metaphase chromosomes from a normal individual and a CCD-affected family member. Normal hybridization signals were observed using this clone on each metaphase examined; however, these signals were restricted to the distal one third of the $6 \mathrm{p}$ arm, localizing BMP6 to the 6p23-p24 band region (Fig. 3). Therefore, even though BMP6 is located on $6 \mathrm{p}$, it appears by FISH to be too far distal to be a candidate for CCD since markers shown to be nonrecombinant with CCD are localized to chromosome 6p21.1-p21.2 [Feldman et al., 1995; Gelb et al., 1995; Mundlos et al., 1995; Ramesar et al., 1996; Volz et al., 1994].
TABLE II. D6S2257 Allele Sizes and Frequencies

\begin{tabular}{lc}
\hline Size of allele & Frequency \\
\hline 201 & 0.0098 \\
199 & 0.0098 \\
195 & 0.0294 \\
193 & 0.0196 \\
189 & 0.0098 \\
187 & 0.0098 \\
185 & 0.1078 \\
183 & 0.1176 \\
181 & 0.2059 \\
179 & 0.1961 \\
177 & 0.1961 \\
171 & 0.049 \\
\end{tabular}

In order to confirm the apparent separation of BMP6 from the CCD chromosomal region, we derived a polymorphic marker, D6S2257, from the P1 genomic clone, and used this for molecular typing of the family. Using 51 unrelated individuals, this STS showed 13 different alleles ranging in size from 171 to 201 base pairs with $85 \%$ heterozygosity and a PIC of 0.83 (Table II). Amplification was specific for the P1 clone DNA from which the STS was derived and occurred only for somatic cell hybrids containing human chromosome 6 (data not shown). Instability in the size of the larger PCR products of this STR was observed and is presumed to be the result of variability in the lengths of several different repeated motifs within the STS. Those meioses showing instability were excluded from the linkage analysis. Multiple recombinants between CCD and the new P1-BMP6 genomic clone marker were identified in this family giving a LOD score of -2 at $\theta=$ 0.14 . Therefore, by genetic marker analysis and by cytogenetic localization, BMP6 is excluded as a candidate for CCD.

\section{DISCUSSION}

We have localized the human CCD gene to a $7 \mathrm{cM}$ region on $6 \mathrm{p} 21$ in agreement with other investigators [Feldman et al., 1995; Gelb et al., 1995; Mundlos et al., 1995; Ramesar et al., 1996]. The identification in our study of a recombination between D6S451 and D6S459, taken together with the data of Mundlos et al. showing

\section{CCD}

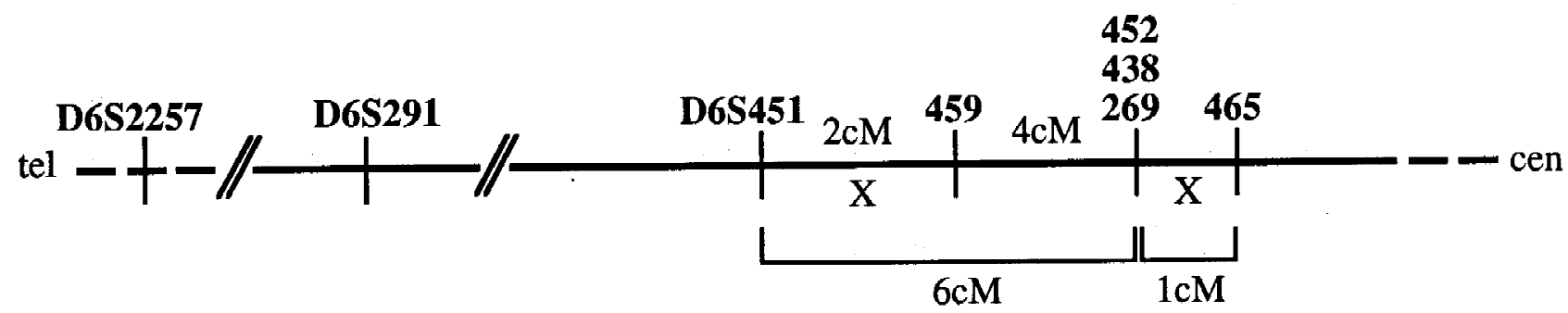

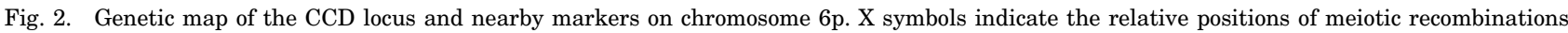

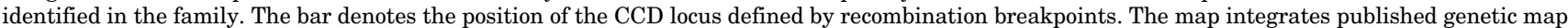
distances [Gyapay et al., 1994]. 

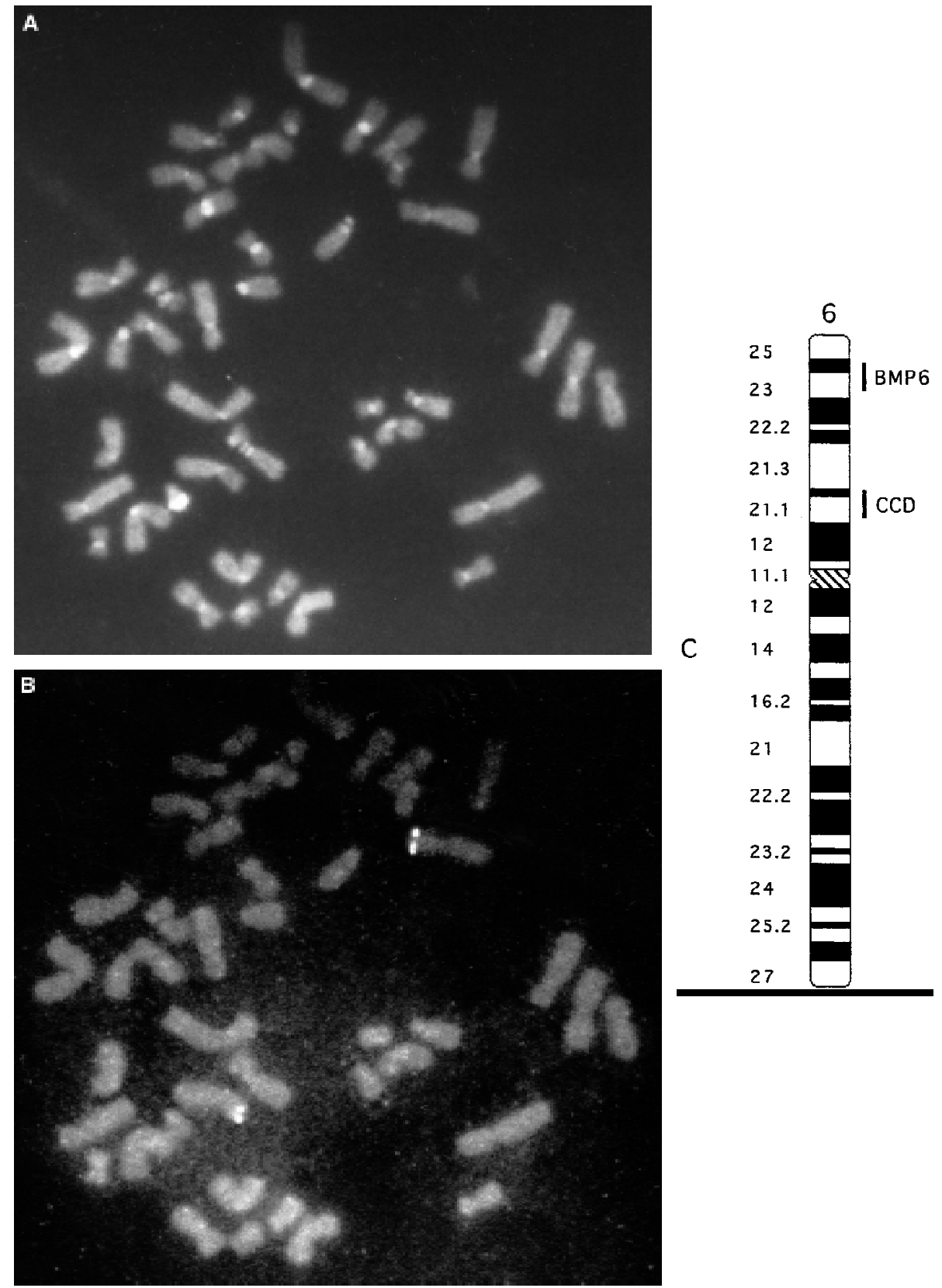

Fig. 3. FISH on normal metaphase chromosomes with a P1 clone isolated by BMP6-specific PCR and hybridization. A: A metaphase chromosome spread counterstained with DAPI shows the overall chromosome morphology and the position of the centromere. B: The same spread counterstained with propidium iodide showing the FITC hybridization signals. C: A chromosome 6 idiogram is provided to illustrate the relative positions of the $6 \mathrm{p} 23$-p24 and 6p21.1-p21.2 regions.

a recombination distal to $\mathrm{D} 6 \mathrm{~S} 438$, indicates that CCD is located in a region probably smaller than $6 \mathrm{cM}$ between D6S451 and D6S438. For all markers tested, no evidence of a microdeletion could be observed in the family reported here. We have used FISH to localize the BMP6 gene to chromosome band region 6p23-p24 and have identified several recombinations between CCD and a marker near BMP6 in this family, thereby excluding this gene from further consideration as a candidate for CCD. Screening for mutations in this region must await the identification of genes within contigs of genomic clones spanning the CCD genetic interval. Ad- ditional families and more markers will help to narrow the region in which to search for the CCD gene. Work with the $C c d$ mutation in mice [Sillence et al., 1987] will also facilitate the identification of the human CCD locus.

\section{ACKNOWLEDGMENTS}

We dedicate this paper to the memory of James $\mathrm{H}$. Asher, Jr. who died during the course of these studies but whose energy and enthusiasm for genetics will live on in us. We thank the members of the CCD family presented here who gave their time for physical exami- 
nations, photographs, and blood sampling and for their wonderful hospitality. Personal funds of J.W.I. and J.H.A. supported much of the work involved in collecting the blood samples and examining the family members. We wish to thank Dr. Dave Law of the University of Michigan Genome Resources Core for help with P1 screening. J.W.I. was supported in part by a University of Michigan Multipurpose Arthritis and Musculoskeletal Diseases Center Grant NIH 5P60AR20557 and by the Scott Collins Memorial Fund. T.B.F., Y.L. and A.W. were supported (in part) by research grant RO1DC02407 from the National Institute of Deafness and other Communication Disorders, National Institutes of Health.

\section{REFERENCES}

Brueton L, Reeve A, Ellis R, Husband P, Thompson E, Kingston H (1992): Apparent cleidocranial dysplasia associated with abnormalities of $8 \mathrm{q} 22$ in three individuals. Am J Med Genet 43:612-618.

Celeste A, Iannazzi J, Taylor R, Hewick R, Rosen V, Wang E, Wozney J (1990): Identification of transforming growth factor $\beta$ family members present in bone-inductive protein purified from bovine bone. Proc Natl Acad Sci USA 87:9843-9847.

Chitayat D, Hodgkinson K, Azouz E (1992): Intrafamilial variability in cleidocranial dysplasia: A three generation family. Am J Med Genet 42:298-303.

Feldman G, Robin N, Brueton L, Robertson E, Thompson E, Siegel-Gartelt J, Gasser D, Bailey L, Zackai E, Muenke M (1995): A gene for cleidocranial dysplasia maps to the short arm of chromosome 6. Am J Hum Genet 56:938-943.

Gelb B, Cooper E, Shevell M, Desnick R (1995): Genetic mapping of the cleidocranial dysplasia (CCD) locus on chromosome band 6p21 to include a microdeletion. Am J Med Genet 58:200-205.

Gorlin RJ, Cohen MM Jr, Levin LS (1990): "Syndromes of the Head and Neck," Third Ed. New York: Oxford University Press, pp 249-253.

Gyapay G, Morissette J, Vignal A, Dib C, Fizames C, Millasseau P, Marc S, Bernardi G, Lathrop M, Weissenbach J (1994): The 1993-94 Genethon human genetic linkage map. Nat Genet 7:246-339.

Hahn G, Cohen R, Wozney J, Levitz C, Shore E, Zasloff M, Kaplan F (1992):
A bone morphogenetic subfamily: Chromosomal localization of human genes for BMP5, BMP6, and BMP7. Genomics 14:759-762.

Jensen B, Kreiborg S (1990): Development of the dentition in cleidocranial dysplasia. J Oral Pathol Med 19:89-93.

Lyons K, Graycar J, Lee A, Hashmi S, Lindquist P, Chen E, Hogan B, Derynck R (1989): Vgr- 1, a mammalian gene related to Xenopus Vg-1, is a member of the transforming growth factor $\beta$ gene superfamily. Proc Natl Acad Sci USA 86:4554-4558.

Mundlos S, Mulliken J, Abramson D, Warman M, Knoll J, Olsen BR (1995): Genetic mapping of cleidocranial dysplasia and evidence of a microdeletion in one family. Hum Mol Genet 4:71-75.

Neinhaus H, Mau U, Zang K, Henn W (1993): Pericentric inversion of chromosome 6 in a patient with cleidocranial dysplasia. Am J Med Genet 46:630-631.

Ott J (1991): “Analysis of Human Genetic Linkage.” Baltimore: Johns Hopkins Press.

Ramesar R, Greenberg J, Martin R, Goliath R, Bardien S, Mundlos S, Beighton P (1996): Mapping of the gene for cleidocranial dysplasia in the historical Cape Town (Arnold) kindred and evidence for locus homogeneity. J Med Genet 33:511-514.

Sillence DO, Ritchie HE, Selby PB (1987): Animal model: Skeletal anomalies in mice with cleidocranial dysplasia. Am J Med Genet 27:75-85.

Spranger JW, Langer LO, Wiedemann H-R (1974): "Bone Dysplasias: An Atlas of Constitutional Disorders of Skeletal Development." Philadelphia: W.B. Saunders, pp 254-257.

Sternberg N (1990): Bacteriophage P1 cloning system for the isolation, amplification, and recovery of DNA fragments as large as 100 kilobase pairs. Proc Natl Acad Sci USA 87:103-107.

Sternberg, N (1992): Cloning high molecular weight DNA fragments by the bacteriophage P1 system. Trends Genet 8:11-16.

Volz A, Boyle JM, Cann HM, Cottingham RW, Orr HT, and Ziegler A (1994): Report of the second international workshop on human chromosome 6. Genomics 21:464-472.

Weber JL, Wang Z, Hansen K, Stephenson M, Kappel C, Salzman S, Wilkie P, Keats B, Dracopoli N, Brandriff B, Olsen A (1993): Evidence for human meiotic recombination interference obtained through construction of a short tandem repeat-polymorphism linkage map of chromosome 19. Am J Hum Genet 53:1079-1095.

Wilke CM, Hall B, Hoge A, Paradee W, Smith D, Glover T (1996): FRA3B extends over a broad region and contains a spontaneous HPV16 integration site: Direct evidence for the coincidence of viral integration sites and fragile sites. Hum Mol Genet 5:187-195. 